we would then, at last, be able to align the treatment with the disease, a fundamental principle of responsible medicine.

Addendum. I coauthored an article on health care reform and its underlying issues in 1994, and although it was written fifteen years ago, some of the concepts within this article may be relevant today (1). In addition, a recent article in the Atlantic magazine addresses key issues underlying this discussion that I find quite compelling but could not address due to considerations of length (2).

\section{Jeffrey S. Flier}

Harvard Medical School, Boston, Massachusetts, USA. E-mail: jeffrey_flier@hms. harvard.edu.
J. Clin. Invest. 119:2850-2852 (2009). doi:10.1172/JCI41033.

1. Flier, J.S., and Maratos-Flier, E. 1994. Health care reform: a free market perspective. Diabetes Reviews. 2:359-367. http://ecommons.med.harvard.edu/ec_ res/nt/A29698DD-A40C-4FD2-9926-718E04778B37/ HealthCareReform_Paper_Fall1994.pdf.

2. Goldhill, D. 2009. How American health care killed my father. The Atlantic. http://www.theatlantic. com/doc/200909/health-care.

\title{
Academic medicine and real health care reform
} n searching for ways to improve health care quality, cost, delivery, and access, the current debate has paid little attention to a group of well-established health care providers whose example might offer a reform solution. Academic health systems (AHSs) - those combining teaching and research activities with clinical delivery - have long provided high-quality care to millions of Americans, including nearly half of the uninsured, and are already located in close proximity to the great majority of the nation's population.

Spurred by the Clinton health initiative in the early 1990s, AHSs developed mechanisms to improve quality, reduce costs, and, in some cases, take financial risk for patients. In effect, over nearly two decades, dozens of these regional health systems have developed, usually, but not always, evolving from the traditional academic medical center. Today, these new entities generally consist of a medical school, multiple hospitals, major ambulatory care centers, and often contractual (if not ownership) relationships with many widely distributed and easily accessible primary care practices, rehabilitation facilities, home infusion and hospice services, and nursing homes. Most have implemented an electronic medical record, and many are putting in place "best practice" algorithms or guidelines as well as outcome measures. The faculty physician groups and hospitals contract as single entities, allowing physician compensation including bonuses to be designed to reward desired outcomes as appropriate, and they are organized to assume financial risk. Indeed, the formation of the University of Pennsylvania Health System as a fully integrated AHS as described above was formally approved by the University of Pennsylvania Trustees on June 18,1993 , as one of the first, if not the first, of these new entities. Finally, the concept of being a "must-have" health system from the standpoint of the patient, and hence the payer, has quickly evolved. Going forward, these regional health systems might be effectively used collectively as the basis for a new system of care nationally.

Key to the AHS model where the provider assumes financial risk is that savings resulting from improving care and streamlining the medical infrastructure accrue to the not-for-profit provider, not to a third party such as a private insurance company. Thus, the provider has not only the desire and the ability, but also the financial incentive, to improve medical outcomes and enhance value. Indeed, risk directly assumed by the provider was critical to the success of the Kaiser Permanente system many decades ago.

How would such a new plan be implemented? One approach would be for a payer to define the requirements needed for a health system to qualify and then contract with it to take financial risk and to deliver the care with the desired and agreed-upon outcomes. Multiple approved systems in the same region would be desirable. While gaps would exist in some geographic areas, these could be defined and efforts made to incentivize qualified systems to develop an approach to closing the gap.

How would coverage be extended to the tens of millions of uninsured and underinsured? At the present time, nearly $50 \%$ of the uninsured are provided care by the nation's academic medical centers and systems. They have been able to do this because of their commitment to provide care to anyone who needs it and their ability to identify some financial coverage for these patients as well as write off bad debt. For some institutions, this latter loss may amount to hundreds of millions of dollars per year. An improved payment methodology for the $50 \%$ of the patients already being cared for as well as new coverage for the remaining $50 \%$ of the patients now directed to these institutions would be expensive, but probably not close to the costs currently under discussion. Importantly, this would provide much-needed financial support for the nation's AHSs, which would be in the best position to apply it to improving the quality of cost-effective care that we are all seeking.

Two final comments are in order on the advantage of using the nation's AHSs to serve as the central focus of an effort to implement health care reform. These systems serve as the major source of education and training for our physicians as well as for many other providers of care, and hence this approach to health care would be rapidly conveyed to the next generations of providers. These organizations also conduct the majority of the basic biomedical research funded by the NIH. Here, too, the possibility of maximizing the translation of these advances to improving patient care also exists.

As with any other proposal to solve the immense problems in health care today, there are surely issues and holes that will need to be worked out. Indeed, one can be certain that this proposal is not a fast and easy fix, but it does emphasize an approach that provides for fundamental changes and that deserves serious consideration as the discussion of health care reform intensifies.

It is paradoxical that the much-maligned Clinton plan of the early 1990s was a major stimulus for this quiet revolution in health care delivery now under way. I believe the AHSs spawned by that initiative now represent a major opportunity to achieve real health care reform.

\section{William N. Kelley}

University of Pennsylvania School of Medicine, Philadelphia, Pennsylvania, USA. E-mail: kelleyw@mail.med.upenn.edu.

J. Clin. Invest. 119:2852 (2009). doi:10.1172/ JCI40986. 